\title{
Study on the settlement of raft foundations by different methods
}

\author{
Vinh Le Ba ${ }^{*}$, Nhan Nguyen Van and Khanh Le Ba \\ Ho Chi Minh City University of Technology, VNU-HCM, Vietnam
}

\begin{abstract}
In order to study effects of the size, the stiffness of foundation, and the applied load on the thickness of compressed zone and the settlement of raft foundations, this paper analyze methods of settlement calculation such as the method of summation of partial settlements, the method of elastic layer of finite thickness, and the finite element method with the PLAXIS 3D software. Effects of the size of foundation are considered with many areas of foundation such as $150 \mathrm{~m}^{2}, 338 \mathrm{~m}^{2}, 600 \mathrm{~m}^{2}, 938 \mathrm{~m}^{2}, 1350 \mathrm{~m}^{2}, 1838 \mathrm{~m}^{2}$, and $2400 \mathrm{~m}^{2}$; and effects of the applied load of the upper structure are considered with many values of $150 \mathrm{kN} / \mathrm{m}^{2}, 200 \mathrm{kN} / \mathrm{m}^{2}$, and $250 \mathrm{kN} / \mathrm{m}^{2}$. There are remarkable differences between settlements calculated by the analytical methods and ones simulated by PLAXIS 3D. From the analysis and evaluation of calculated results, this paper proposes a suitable method to determine the thickness of compressed zone, as well as the method of calculation of settlement for raft foundations.
\end{abstract}

\section{Introduction}

Normally, settlement of raft foundations can be calculated by the method of summation of partial settlements, or the method of elastic layer of finite thickness for the specific cases of soil condition [1]. Regarding to the method of summation of partial settlements, the settlement is calculated at a point and the foundation's stiffness is not taken into account. However, for the cases of large size foundation the average settlement of foundation must be considered by calculating the settlement at different positions of foundation.

For the method of elastic layer of finite thickness, the settlement results of the foundation mainly depends on the thickness of compressed zone which can be effected by the size of the foundation, the applied load of upper buildings, and the soil condition [1], [2], [3]. Theoretically, the thickness of compressed zone are frequently determined by TCVN 9362: 2012 [1], JGJ6-99 [3], or the methods of K.E. Egorov, B.L. Dalmatov [2], [4], [5]. However, the thickness of the compressed zone calculated by these methods can results in very large differences. Therefore, this paper analyse a suitable way of determining the thickness of compressed zone.

\footnotetext{
* Corresponding author: lebavinh@hcmut.edu.vn
} 


\section{Methods of estimating settlement of raft foundations}

According to TCVN 9362: 2012 [1], for a large foundation which its width or diameter is greater than $10 \mathrm{~m}$ the calculated thickness of the compressed zone is firstly determined. If the compressed zone includes a soil layer which its modulus of deformation is smaller than $10 \mathrm{MPa}$, or below this zone if there is a soil layer which its modulus of deformation is smaller than $10 \mathrm{MPa}$ and its thickness is more than $5 \mathrm{~m}$, the settlement is calculated by the method of summation of partial settlements, otherwise it can be calculated by the method of elastic layer of finite thickness.

\subsection{The method of elastic layer of finite thickness}

Based on the method proposed by K.E. Egorov [2], [4], TCVN 9362: 2012 [1] has provided a formula for calculating the settlement of a single foundation as follows:

$$
S=p . B . M \sum_{i=1}^{n} \frac{k_{i}-k_{i-1}}{E_{i}}
$$

Where $p$ : the average pressure at the bottom of the foundation; $B$ : the width of the rectangular foundation, or the diameter of the circular foundation; $M$ : the adjustment coefficient; $k_{i}, k_{i-1}$ : the coefficients of the foundation shape for the $i$ layer, $E_{i}$ : modulus of deformation of the $i$ layer.

For the method of elastic layer, the calculated settlement mainly depends on the thickness of the compressed zone which can be effected by the size of foundations, the applied load, and the soil condition.

According to TCVN 9362: 2012, if the foundation is large and the modulus of deformation of soils is larger than 10MPa the calculated thickness of the elastic layer is determined as follows:

$$
\begin{aligned}
& H_{t t}=9+0,15 B \text { for clay } \\
& H_{t t}=6+0,1 B \text { for sand }
\end{aligned}
$$

On the other hand, according to JGJ6-99 [3] the calculated thickness of the elastic layer is determined by:

$$
H_{t t}=\left(Z_{m}+\xi B\right) \beta
$$
[3].

Where $Z_{m}$ : coefficient determined by the experience [3], $\xi, \beta$ : coefficients determined by

According to K.E. Egorov [2], [4], the value of $H_{t t}$ is determined by the formula (7). Moreover, B.L. Dalmatov [2] proposed the formula to determine the calculated thickness of the elastic layer as follow:

$$
H_{t t}=2 A \omega_{t} \cdot B
$$

Where $A \omega_{t}$ : coefficient determined by [2].

\subsection{The method of summation of partial settlements}

If the compressed zone includes a soil layer which its modulus of deformation is smaller than $10 \mathrm{MPa}$, or below this zone if there is a soil layer which its modulus of deformation is 
smaller than $10 \mathrm{MPa}$ and its thickness is more than $5 \mathrm{~m}$, the settlement is calculated by the method of summation of partial settlements. The settlement at any point on the foundation is calculated, and the foundation's stiffness is not taken into account as the following formula:

$$
S=\sum_{i=1}^{n} S_{i}=\beta \sum_{i=1}^{n} \frac{p_{i} h_{i}}{E_{i}}
$$

Where $S$ : final settlement; $S_{i}$ : final settlement of the $i$ layer; $n$ : number of calculated layers of the compressed zone; $h_{i}$ : thickness of the $i$ layer; $p_{i}$ : the average stress caused by the building at the $i$ layer; $E_{i}$ : modulus of deformation of the $i$ layer; $\beta$ : coefficient of lateral expansion of soil, according to TCVN 9362: $2012 \beta$ is 0.8 .

For large foundations, settlement which is calculated by the above formula will be much larger than the actual settlement of the foundation. Therefore, in case of large size foundation the average settlement should be determined by calculating the settlement at several positions of foundation as Figure 1a. Then the average settlement is determined by the area of (abfe) which satisfies the condition: Area of (abfe) = Area of (abb'ga')

In order to have a simple calculation, the average settlement of the foundation can be calculated by the following formula:

$$
S_{\text {avg }}=\frac{S_{A}+2 S_{B}+2 S_{C}+4 S_{D}+2 S_{E}+2 S_{F}}{13}
$$

Where $S_{a v g}$ : average settlement of the foundation; $S_{A}, S_{B}, S_{C}, S_{D}, S_{E}$, and $S_{F}$ : settlement calculated at points of A, B, C, D, E, F, respectively.

One of the most important factors that directly affect the settlement is the thickness of the compressed zone. So far, to determine this thickness there are many points of view.
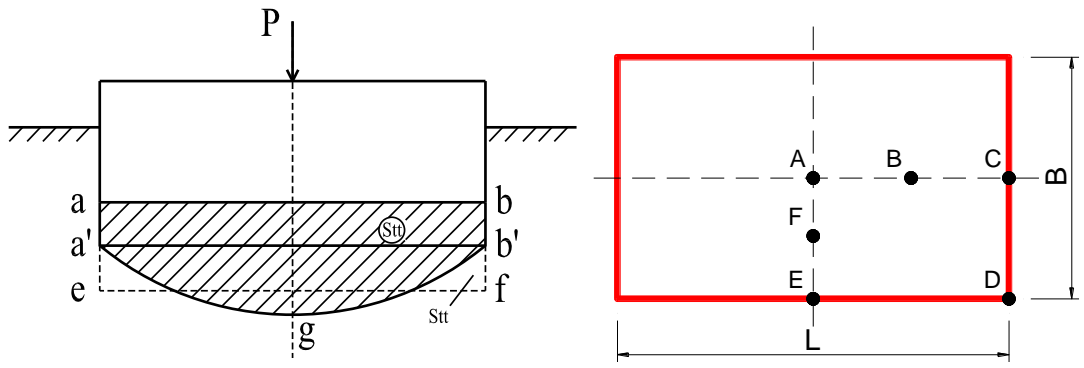

a)

b)

Fig. 1. a) The principle of calculating the average settlement of the foundation; b) Points of the settlement calculation

According to TCVN 9362: 2012, the compressed zone is approximately determined by the following condition:

$$
\sigma_{z} \leq 0,2 \sigma_{z}^{b t}
$$

Where $\sigma_{z}$ : the stress caused by the building, $\sigma_{z}^{b t}$ : the stress caused by the soil's weight.

In fact, when calculating the settlement of the raft foundation by the condition (7), and calculating by the condition that there is no $\sigma_{z}$ at the depth of the compressed zone, calculation results could be remarkable different. For the large size foundations, if the 
formula (5) is used to predict the final settlement, the compressed zone should be determined at the depth where there is no additional stress caused by the upper building.

\subsection{Calculation of settlement by using the finite element method}

In addition to the analytical methods, this paper uses PLAXIS software [6] with the hardening soil model to calculate the settlement of raft foundations. With this model the soil stiffness changes with the stress in the ground, and is consistent with the behavior of many types of soils [7], [8]. The average settlement of the foundation is calculated by the formula (6), by using the settlement of the points in Figure $1 \mathrm{~b}$.

\section{Estimating settlement of a raft foundation, a case study}

In order to compare the observed and the predicted settlements by different methods, the structure chosen for this study was a circular water standpipe located in the east-central Iowa [9]. A shallow foundation of reinforced concrete was used and consisted of a circular mat $8.4 \mathrm{~m}$ in diameter located $1.4 \mathrm{~m}$ below existing ground surface.

The 18.3m-tall standpipe was made of steel plate, and therefore the net dead load of the structure (dead load minus foundation excavation) is relatively small, $77.5 \mathrm{kN}$; the majority of additional load being exerted by the live load weight of water, $4631 \mathrm{kN}$. The geometry of the foundation is such that the system was analyzed as a rigid mat, thus the settlement was assumed to be uniform.

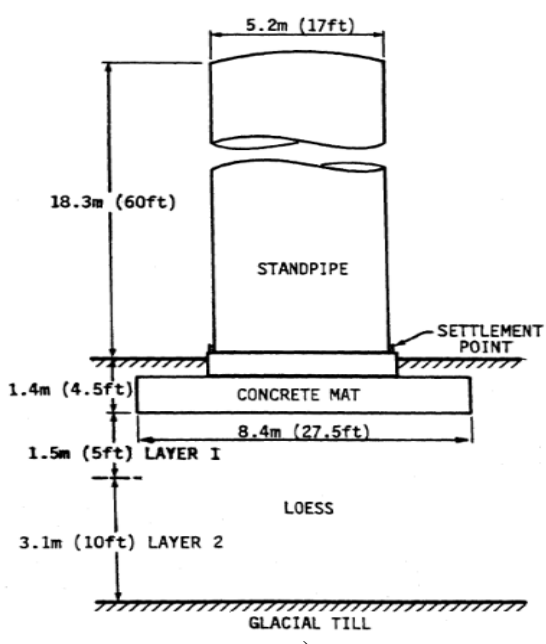

a)

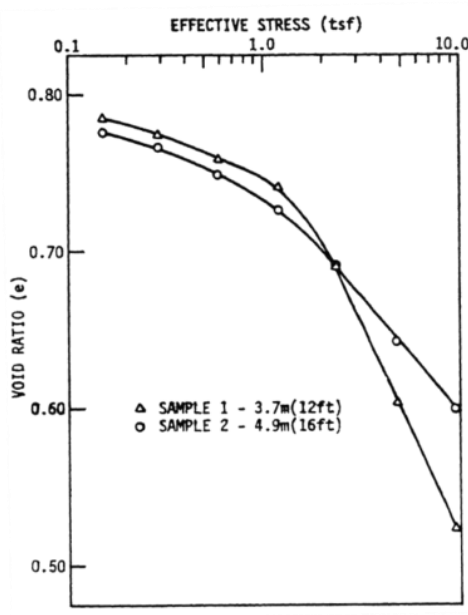

b)

Fig.2. a) Foundation schematic of Oxford standpipe [9]; b) Oedometer results on loess at natural moisture content [9]

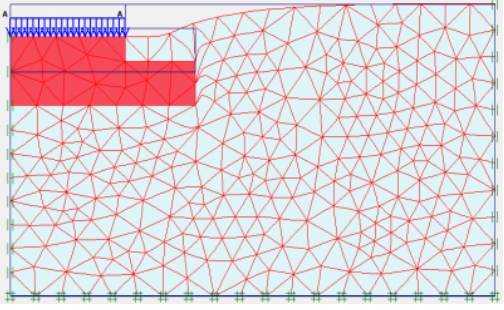

a)



b)

Fig. 3. a) Ground displacement simulated by Plaxis 2D; b) Observed settlement versus time 
A schematic of the structure and subsurface soil conditions is shown in Figure 2a. The soil profile at the site consists of $6 \mathrm{~m}$ of Peorian-age loess overlying a relatively thin, $0.9 \mathrm{~m}$, glacial till-derived buried clay soil, underlain by dense glacial till. Undisturbed samples for oedometer testing were obtained at depths of $3.7 \mathrm{~m}$ and $4.9 \mathrm{~m}$ below ground surface. Results of these two tests are shown in Figure 2b.

The observed settlement versus time data are shown in Figure 3b. Settlement measurements obtained in 1981 and 1983 would indicate that settlement is essentially complete.

Settlement predictions were made by several methods, however the assumptions used in each method were the same: all deformations were assumed to take place within the loess, i.e., the glacial till was assumed incompressible; the average contact stress was used in settlement calculations; Poisson's ratio is 0.3 .

Settlement calculations based on the methods previously described gave varying results as summarized in Table 1. The difference between the observed settlement and the result of the method of summation of partial settlements was $40 \%$. Settlement simulated by Plaxis $2 \mathrm{D}$ was approximately equal to the observed settlement. In addition, the settlement of the method of elastic layer was smaller than the observed settlement with a difference of $21 \%$.

Table 1. Comparison of observed and predicted settlement.

\begin{tabular}{|c|c|c|}
\hline Method & $\begin{array}{c}\text { Settlement } \\
(\mathrm{mm})\end{array}$ & $\begin{array}{c}\text { Predicted settlement / } \\
\text { Observed settlement }\end{array}$ \\
\hline Observation & 33 & 1 \\
\hline Plaxis 2D & 34 & 1.03 \\
\hline $\begin{array}{c}\text { The method of summation of } \\
\text { partial settlements }\end{array}$ & 46 & 1.4 \\
\hline $\begin{array}{c}\text { The method of elastic layer of } \\
\text { finite thickness }\end{array}$ & 26 & 0.79 \\
\hline
\end{tabular}

\section{Parameter studies on the settlement of raft foundations}

In order to study the effects of foundation's size, and the applied load on the compressed zone as well as the settlement results, the predictions were carried out on foundations of different sizes of $(10 \times 15) \mathrm{m}^{2},(15 \times 22.5) \mathrm{m}^{2},(20 \times 30) \mathrm{m}^{2}$, $(25 \times 37.5) \mathrm{m}^{2}$, $(30 \times 45) \mathrm{m}^{2}$, $(35 \times 52.5) \mathrm{m}^{2}$, and $(40 \times 60) \mathrm{m}^{2}$; each foundation is subjected to the uniform loads of 150 $\mathrm{kN} / \mathrm{m}^{2}, 200 \mathrm{kN} / \mathrm{m}^{2}$, and $250 \mathrm{kN} / \mathrm{m}^{2}$; the parameters of soils and foundations are given in Table 2 . The settlement was calculated by the following methods:

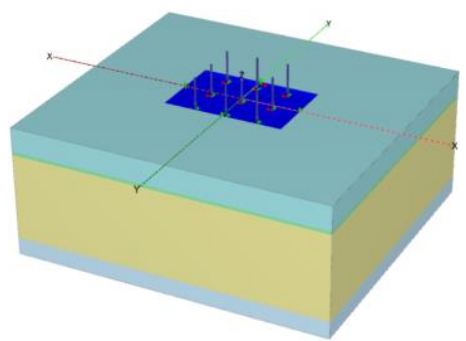

a)

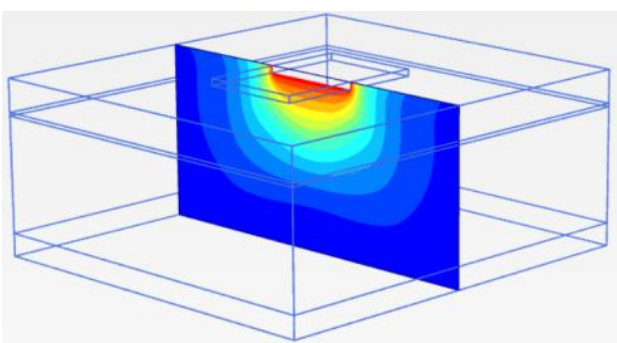

b)

Fig. 4. a) Computational model by Plaxis 3D; b) Contour of vertical displacements 
- Firstly, the method of summation of partial settlements was applied with the depth of the compressed zone is determined by the condition (7), and then by the depth where there is no $\sigma_{\mathrm{z}}$ caused by the applied load.

- Also, the settlement was determined by the method of elastic layer of finite thickness as the guidances by TCVN 9362: 2012, JGJ6-99, and K.E.Egorov, B.L. Dalmatov.

- Moreover, the numerical simulations were carried out by the Plaxis 3D software [10].

Table 2. Soil's parameters in the Hardening - Soil model.

\begin{tabular}{|c|c|c|c|c|c|c|}
\hline Soil layer & $\begin{array}{c}\text { Layer 1: } \\
\text { Sandy clay }\end{array}$ & $\begin{array}{c}\text { Layer 2: } \\
\text { Clayey } \\
\text { sand }\end{array}$ & $\begin{array}{c}\text { Layer 3: } \\
\text { Clayey sand- } \\
\text { silty sand }\end{array}$ & $\begin{array}{c}\text { Layer 4: } \\
\text { Fat clay - } \\
\text { lean clay }\end{array}$ & $\begin{array}{c}\text { Layer 5: } \\
\text { Clayey sand - } \\
\text { silty sand }\end{array}$ & Foundation \\
\hline Type & Drained & Drained & Drained & Drained & Drained & $\begin{array}{c}\text { Linear } \\
\text { elastic }\end{array}$ \\
\hline$\gamma_{\text {unsat }}\left(\mathrm{kN} / \mathrm{m}^{3}\right)$ & 20.25 & 19.93 & 20.12 & 21.06 & 20.98 & 25 \\
\hline$\gamma_{\text {sat }}\left(\mathrm{kN} / \mathrm{m}^{3}\right)$ & 21.25 & 19.93 & 20.12 & 21.06 & 20.98 & \\
\hline $\mathrm{E}_{50}{ }^{\text {ref }}\left(\mathrm{kN} / \mathrm{m}^{2}\right)$ & 22068 & 12195 & 26129 & 27697 & 42434 & 30000000 \\
\hline $\mathrm{E}_{\mathrm{oed}}\left(\mathrm{kN} / \mathrm{m}^{2}\right)$ & 22068 & 12195 & 26129 & 27697 & 42434 & \\
\hline $\mathrm{E}_{\mathrm{ur}}{ }^{\text {ref }}\left(\mathrm{kN} / \mathrm{m}^{2}\right)$ & 66204 & 36585 & 78387 & 83091 & 127302 & \\
\hline $\mathrm{m}$ & 0.8 & 0.7 & 0.6 & 1 & 0.6 & \\
\hline$v_{\mathrm{ur}}$ & 0.2 & 0.2 & 0.2 & 0.2 & 0.2 & 0.2 \\
\hline $\mathrm{c}\left(\mathrm{kN} / \mathrm{m}^{2}\right)$ & 9.8 & 7.70 & 5.70 & 4.20 & 6.20 & \\
\hline$\varphi\left(^{\circ}\right)$ & 28.98 & 30.10 & 29.92 & 31.28 & 30.87 & \\
\hline$\psi\left({ }^{\circ}\right)$ & 0.00 & 0.10 & 0.00 & 1.28 & 0.87 & \\
\hline $\mathrm{p}_{\mathrm{ref}}\left(\mathrm{kN} / \mathrm{m}^{2}\right)$ & 100 & 100 & 200 & 300 & 300 & \\
\hline Thickness $(\mathrm{m})$ & 9.5 & 1.0 & 33.0 & 14.3 & 30.0 & 2.5 \\
\hline
\end{tabular}

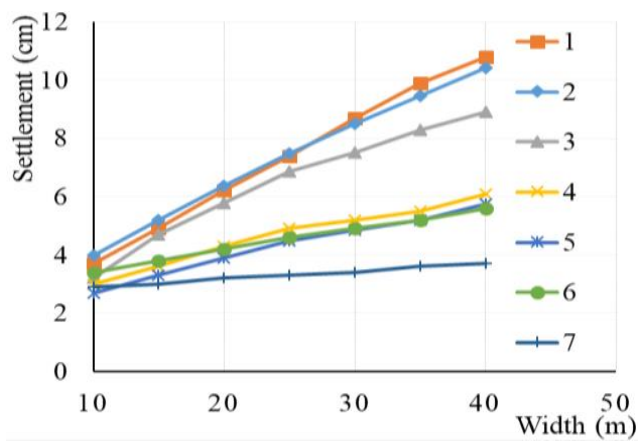

a)

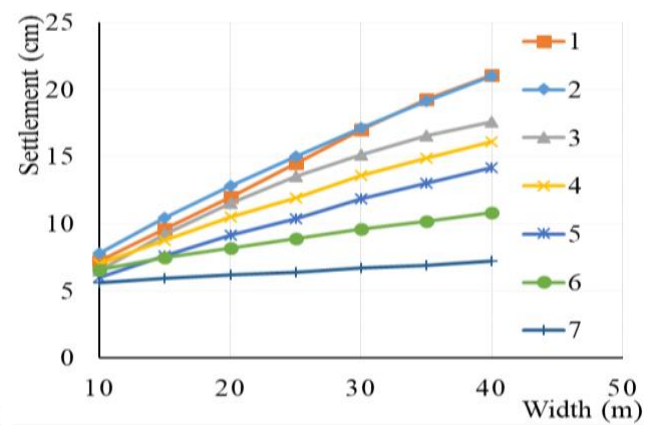

b)

Fig. 5. Relationship between the settlement and the width of raft foundation due to different applied loads: a) $\mathrm{p}=150\left(\mathrm{kN} / \mathrm{m}^{2}\right)$; b) $\mathrm{p}=250\left(\mathrm{kN} / \mathrm{m}^{2}\right)$. The thickness of compressed zone is determined by different methods: 1 - by B.L. Dalmatov; 2- by condition of $\sigma_{z}=0$; 3- by Plaxis 3D; 4-by K.E. Egorov; 5- by condition (7); 6- by JGJ6-99; 7- by TCVN 9362:2012. 




a)

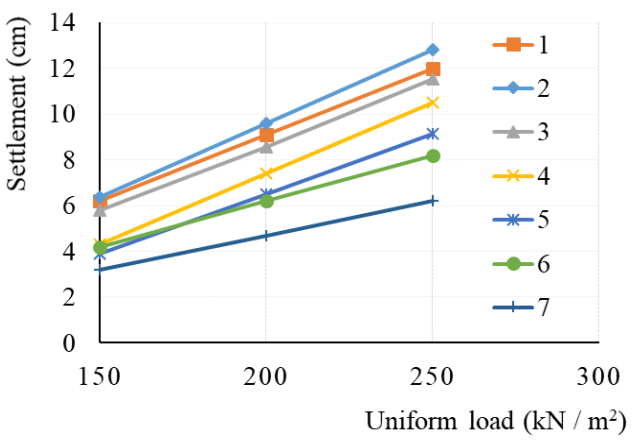

b)

Fig. 6. Relationship between the settlement and the applied load for foundations of different widths: a) $\mathrm{B}=10 \mathrm{~m} ; \mathrm{b}) \mathrm{B}=20 \mathrm{~m}$. The thickness of compressed zone is determined by different methods: 1- by B.L. Dalmatov; 2- by condition of $\sigma_{z}=0 ; 3$ - by Plaxis 3D; 4-by K.E. Egorov; 5- by condition (7); 6by JGJ6-99; 7- by TCVN 9362:2012.

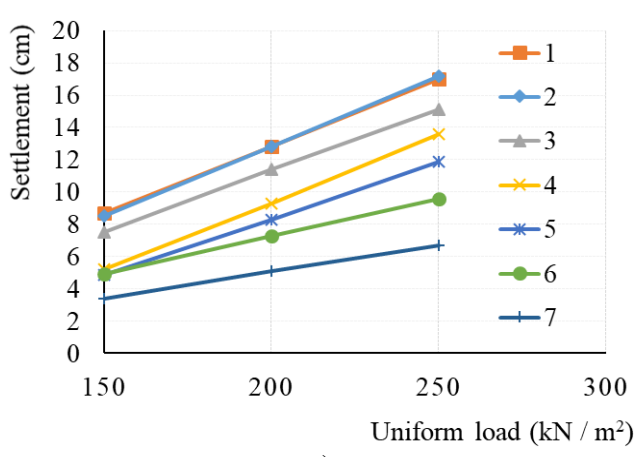

a)

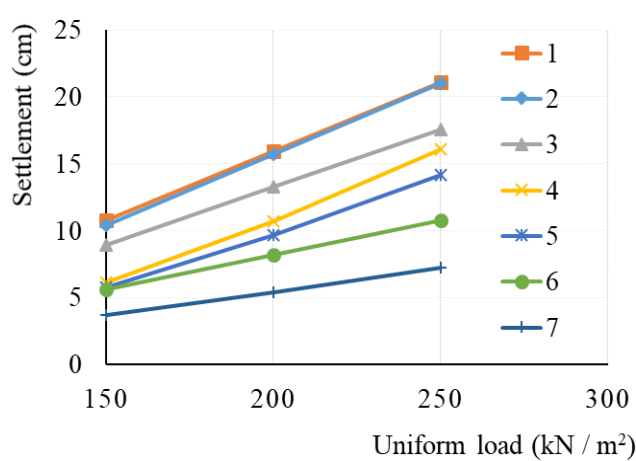

b)

Fig. 7. Relationship between the settlement and the applied load for foundations of different widths: a) $\mathrm{B}=30 \mathrm{~m}$; b) $\mathrm{B}=40 \mathrm{~m}$. The thickness of compressed zone is determined by different methods: 1 - by B.L. Dalmatov; 2- by condition of $\sigma_{z}=0$; 3- by Plaxis 3D; 4-by K.E. Egorov; 5- by condition (7); 6by JGJ6-99; 7- by TCVN 9362:2012.

Based on the Figure 5 to Figure 7, it can be found that the settlement of the foundation considerably increases as the size of foundation and the load increase. The different methods result in different results of settlement. The settlement calculated by the method of elastic layer has the smallest value as compared with the settlement calculated by the other methods. For the case of $\mathrm{p}=150 \mathrm{kN} / \mathrm{m}^{2}$ and foundation size of $(10 \mathrm{x} 15) \mathrm{m}^{2}$, the largest difference between the calculated settlements is $52 \%$. Moreover, the largest difference between the calculated settlements can be up to $77.1 \%$ for the case of $\mathrm{p}=250 \mathrm{kN} / \mathrm{m}^{2}$ and foundation size of $(40 \times 60) \mathrm{m}^{2}$.

The settlements calculated by the method of summation of partial settlements with the compressed zone determined by the condition of $\sigma_{z}=0$, and the settlements calculated by Dalmatov's method are the same; the difference between these calculated settlements and Plaxis 3D simulation results varies from $8 \%$ to $19 \%$. However, the difference between the simulated settlement and the settlement calculated by the method of elastic layer determined by formula (2) varies from $9.4 \%$ to $59.3 \%$.

Depending on the size of foundation and the load, the settlements calculated by the method of summation of partial settlements with the compressed zone determined by the condition of $\sigma_{z}=0$ have large differences from $23.55 \%$ to $45.15 \%$ with ones calculated by the same method but the compressed zone determined by the formula (2). 


\section{Conclusions}

Results of settlement calculation of the large size foundations mainly depend on the thickness of the compressed zone. Several factors can affect the thickness of this zone such as the size of foundation, the load of structure, and the soil condition.

Analyses mentioned above show that different methods resulted in different values of thickness of the compressed zone. The largest difference between the calculated thicknesses is $452 \%$ for the case of $\mathrm{p}=200 \mathrm{kN} / \mathrm{m}^{2}$ and foundation size of $(40 \times 60) \mathrm{m}^{2}$.

Also, different methods of settlement calculation resulted in different values of settlement. These differences tend to increase as the width of raft foundation increases. The largest difference between the calculated settlements is $77.1 \%$ for the case of $p=250$ $\mathrm{kN} / \mathrm{m}^{2}$ and foundation size of $(40 \times 60) \mathrm{m}^{2}$. The settlements predicted by the method of summation of partial settlements, Dalmatov method, and Plaxis 3D simulation can be similar.

Based on the results of the above parameter studies, to ensure the safety of the structures in case of settlement calculation by the method of summation of partial settlements, the thickness of the compressed zone should be determined at the depth where there is no additional stress caused by the upper building. In order to apply the method of elastic layer of finite thickness, the calculated thickness of the linear elastic layer should be determined by Dalmatov method.

This research is funded by Ho Chi Minh City University of Technology - VNU-HCM under grant number TSĐH-KTXD-2017-26. The authors would like to express a sincere thank to this support.

\section{References}

1. TCVN 9362:2012, Specifications for design of foundation for buildings and structures. (2012)

2. C. N. Vu, Design and calculation of shallow foundation, National University of Civil Engineering, (1998)

3. X. Chen, Settlement Calculation on High-Rise Buildings Theory and Application, (Beijing: Science Press, 2011)

4. K. E. Egorov, On deformation of finite footings: footings, foundations and soil mechanics (Moscow, 1961)

5. N. A. Tsytovich, Soil mechanics, comprehensive study, 5th edition (Lenand Publisher, Moscow, 2014)

6. R. B. J. Brinkgreve, Plaxis reference manual, (Balkema, 2007).

7. R. F. Obrzud, A. Truty, The hardening soil model - a practical guidebook, (Zace Services Ltd, Software engineering, 2018)

8. T. Schanz, P. A. Vermeer, The hardening soil model: Formulation and verification, Beyond 2000 in Computational Geotechnics - 10 Years of PLAXIS, (Balkema, 1999).

9. A. Lutenegger, J. Remmes, D. Bernard, Handfelt, D. Leo, Settlement Performance of a Mat Foundation on Unsaturated Loess. International Conference on Case Histories in Geotechnical Engineering, 1053-1058, (1984)

10. R. B. J. Brinkgreve, Plaxis 3 D reference manual, (Balkema, 2017) 